\title{
Efficiency of alternative electric power industry for poultry farming
}

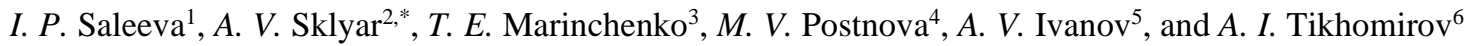 \\ ${ }^{1}$ All-Russian Research and Technological Poultry Institute (the Federal Science Center "VNITIP RAS"), Sergiev Posad, Russia \\ ${ }^{2}$ Big Dutchmen LlC, Moscow, Russia \\ ${ }^{3}$ Rosinformagrotekh FSBSI, Pravdinsky Township, Russia \\ ${ }^{4}$ Volgograd State University, Volgograd, Russia \\ ${ }^{5}$ Smena Breeding and Genetic Center, village of Bereznyaki, Russia \\ ${ }^{6}$ Federal Science Center for Animal Husbandry named after Academy Member L.K. Ernst, Russia
}

\begin{abstract}
The growing poultry industry needs additional energy resources. To improve the efficiency of the energy systems in poultry farms (hereinafter referred to as PF), energy saving options were evaluated by modeling: using different tariffs, changing suppliers, changing the supply voltage, entering the poultry farms to the wholesale electricity and capacity market. Studies have shown that the poultry farms can radically reduce the cost per kilowatt-hour through receiving electricity from an alternative source that works on the saved gas.
\end{abstract}

\section{Introduction}

The poultry industry of the Russian Federation with an annual production of 44-47 billion eggs and more than 4.6 million metric tons of poultry meat is one of the largest energy consumers in the agribusiness: up to $12 \ldots$ $14 \%$ in the cost of its products is the energy component With the growth of production, electricity purchases will also increase, and therefore the issue of the country's energy development prospects and the sustainability of energy prices is extremely important. The state of domestic energy and its problems were objectively evaluated by science (V.E. Fortov, O.N. Favorsky et al.) and energy specialists $[1,2]$. Scientists of the Russian Academy of Sciences (Makarov, A.A., Volkov, E.P. et al.) $[3,4]$, together with the employees of RAO UES, developed a forecast and stages for the prospective development of the industry until 2030, including those for renewable (ocean, etc.) and fundamentally new (alum-hydrogen, distributed energy, etc.) energy resources (Akulinichev, V.A., Fedorov, M.P., Sheidlin, E.E. et al.) [5-7], as well as for further improvement of traditional energy technologies using oil, gas, coal, nuclear energy, etc. (Ponomarev-Stepnoy, I.I. et al.) [8].

\section{Materials and methods}

The R\&D toolkit is based on feasibility (design) studies, which formed the basis of the experimental part, i.e. a large-scale production audit of the mini-electric power plant construction and operation at poultry farms with the generation of up to a third of the of poultry farm own electricity in conditions based on the Cherepovets broiler factory (hereinafter referred to as $\mathrm{ChBF}$ ).

\section{Results}

The cost reduction can be ensured by: the introduction of multi-tariff payments in $\mathrm{kWh}$, requiring the replacement of metering devices with the installation of an Automated information and measuring system of commercial energy metering (AIISKUE) [13]; change of guaranteeing supplier; transfer of farms to receive high voltage electricity (hereinafter referred to as HV) (10, 35 , and $110 \mathrm{kV}$ ); entering PF into the wholesale electricity and capacity market (hereinafter referred to as WECM) [14, 15]; obtaining by PF a part of the "alternative" electricity on inexpensive fuel, e.g. network gas, crude oil, biogas or burning native litter, etc. (Clause 2, Article 9, No. 261-FZ).

The feasibility study to assess the reality of using these options to reduce the price of $\mathrm{kWh}$ at $\mathrm{PF}$ indicates: a WECM member should have at least $20 \mathrm{MW}$ of connected capacity with a minimum power of $750 \mathrm{kVA}$ of each transformer substation, which is not feasible for $\mathrm{PF}$, where a number of workshops with mini-loads are distantly located from the main site through sanitary breaks. Since the establishment of the WECM, no organization has entered this organization.

From 26.03.2003, the process connection of the consumer to the power grids is defined as " ... which is of a single character ..." (Clause 1, Art. 26, No. 35-FZ) and, moreover, the $\mathrm{PF}$ transfer to $\mathrm{HV}$ input is the appearance of risks for network providers and decrease in their income from sales. For these reasons, the transfer to HV

\footnotetext{
* Corresponding author: alexbd2006@mail.ru
} 
cannot be attributed to affordable methods for PF to reduce the cost of $\mathrm{kWh}$.

The powers of the guaranteeing suppliers are defined in detail in Decree No. 442; by region, joint-stock companies, which have been established on the basis of network energy sales, perform their functions at the majority of consumers, the rest ones receive energy from other suppliers. Formally, this has created competitive sales conditions and opportunities for consumers to choose an electricity supplier. But the minimum price of $\mathrm{kWh}$ for each particular PF can be only for the generating company nearest the farm with the cheapest fuel (for example, gas). Several supply options comparable at the price of $\mathrm{kWh}$ can be only at PF in the zones of large industrial centers, but the main poultryfarming capacities are dispersed in the distance from the first ones, where the choice of feeding patterns is unlikely.

One can evaluate the economic feasibility of the use of other tariffs (1-rate and 2-rate tariffs, as well as 1zone and 3-zone tariffs) using the example of Sheksninskaya poultry factory JSC. The initial data are as follows: the annual electricity consumption is $18,637,000 \mathrm{kWh}$, the monthly average is $1,553,000 \mathrm{kWh}$; total transformer power is $12,500 \mathrm{~kW}$; the total load power is $8,500 \mathrm{~kW}$; the annual average hourly constantly used power is 2,128 $\mathrm{kW}$. According to control measurements of electricity consumption, the maximum hourly capacity is $2.4 \mathrm{MW}$ for the summer period and 4.04 MW for the winter period.

Calculation of the application of 1-rate and 2-rate tariffs: In the case of 1-rate tariff, the payment for electricity will be:

$$
\begin{gathered}
1,553,000 \mathrm{kWh} \times 19.54 \mathrm{USD} /{ }^{\prime} 000 \mathrm{kWh}= \\
=30,345,620 \mathrm{USD} .
\end{gathered}
$$

In the case of 2-rate tariff, taking into account the unevenness of the actual summer electricity consumption, the declared peak power should be at least $2,400 \mathrm{~kW}, 4,040 \mathrm{~kW}$ in winter and, accordingly, the payment for it will be 16,985,394 and 28,896,250 USD.

Taking into account surcharges for electricity consumption (10,405 USD), the total costs for electricity in the summer period are $0.027 \mathrm{mln}$ USD and $0.039 \mathrm{mln}$ USD in the winter period, i.e. the 2-rate tariff is unprofitable $(0.027 \mathrm{mln}$ USD) for the farm for the whole year.

Comparison of 1-zone (1-rate) and 3-zone tariffs for electricity:

1-zone (1-rate) tariff: the monthly consumption of electricity for PF is $1,553,000 \mathrm{kWh}$, the price per $1 \mathrm{kWh}$ at the used 1-zone tariff is 0.019 USD / $\mathrm{kWh}$ (price for farms with HV electricity networks); the consumption of funds for payment for electricity amounts to:

$$
\text { 1,553,000 kWh } \times 0.019 U S D / k W h=30,356.87 .
$$

The 3-zone tariff, according to the data of regime days 20.06 and 20.12 (the timing of conducting control measurements of the electricity consumption of $\mathrm{PF}$ jointly with representatives of electrical grid companies), the following load levels and temporary boundaries of three zones of electrical energy consumption with different intensity has been determined by the hour of day: $19.45 \%$ of monthly electricity consumption at night hours from $23: 00$ to $05: 00,19.15 \%$ in the period of semi-peak loads at 17:00... 22:00, and $61.4 \%$ in the peak consumption zone at $05: 00 \ldots 16: 00$. The current rates for the 3-zone tariff are for our case as follows: peak is 0.028 , half-peak is 0.019 and night is $0.013 \mathrm{USD} / \mathrm{kWh}$. Payment for monthly electricity consumption at the 3zone tariff will be: $1,553,000 \times 0.1945 \times 0.013=$ $3,926.76$ USD for night hours; $1,553,000 \times 0.1915 \times$ $0.019=2,012$ USD for the period of half-peak; $1,553,000 \times 0.614 \times 0.028=26,699.176$ USD for the period of peak loads. Total for the month at the 3 -zone tariff the payment is $36,450.685$ USD. Conclusion is that the transition to the 3-zone tariff is unprofitable for PF; it will overpay 6,098 USD per month. In addition, in order to switch to a multi-zone settlement system, the farm should invest certain funds to replace electricity metering devices.

Let us examine the issue of the production of own electric power storage system (alternative source). For the practical evaluation of the scheme based on the Cherepovets Broiler Factory (hereinafter referred to as $\mathrm{ChBF}$, which is part of the same APK-OGO association), the first at the poultry farms of the Russian Federation mini-electric power plant was built (hereinafter referred to as MEPP) at the gas boiler house. To generate its own electric power, a $1.25 \mathrm{MW}$ electric generator was manufactured complete with a steam turbine. The boiler room consisted of the three DKVR-20-13GM boilers, one of them had an incomplete load; there was enough free power to supply the turbine, and the ChBF, after having introduced heat recovery units in most poultry houses, saved enough gas to generate up to one third of the required electricity

\section{Discussion}

We prepared the "Concept (main provisions) of the technical policy in the electric power industry of Russia for the period up to 2030" [9], two laws on electric power industry No. 35-FZ and No. 261-FZ $[10,11]$ were adopted, as well as Decree No. 442 of the Government of the Russian Federation [12] was issued. These regulatory documents envisaged: energy saving, increasing energy efficiency, low-cost modernization and fast payback of improved power systems, supply of energy resources to the consumer at affordable rates, i.e. measures to stabilize the selling prices of $\mathrm{kWh}$ with the possibility of reducing them.

One of the most effective options of the estimated options for reducing the cost of electricity for PF could be the generation of own electricity. The ten-year operating experience of this workshop with an annual output of 3.0 million $\mathrm{kWh}$ per year (this is approximately $32 \%$ of the total PF demand) showed that the cost of 1 $\mathrm{kWh}$ produced by such a unit is 2.6-3.2 times lower than the network price, which reduced the annual payment for 
electricity by $20 \%$ in the whole factory. The calculation showed that during the PF production of half the electricity payments will decrease by one third.

The task is not $100 \%$ replacement of power grids, however, they are to cover $45-55 \%$ of the needs of the factory and serve as a reserve.

Under the conditions of electricity generation by two gas installations (gas piston engine, GPE) and an electric generator (the scheme having a network gas CHP, there are eight of them with transmission networks) it is possible to achieve a reduction of a third. Here it is important not only that the GPE has an efficiency of up to $44 \%$ (and a steam turbine efficiency is up to $39 \%$ ), but also the remoteness of CHP from the poultry farm, since electricity is charged through several network regions.

The long-term operation of the MEPP at the Cherepovets Broiler Factory also made it possible to substantiate a number of requirements for such stations: a MEPP should be based not on a turbine (including a gas turbine), but on a GPE. In addition to higher efficiency, change in load and external temperatures does not affect its efficiency as in turbines; the start of GPE is performed for 2-3 minutes (a turbine starts 5 times longer); the number of starts of GPE is not limited and does not affect its life; GPE works at a gas pressure of 150-3,000 mbar; the turbine has a shorter lifetime; GPE CAPEX is $21 \%$ lower. GPE has the advantage over diesel engines in cheaper fuel and three times lower NOx emissions. Therefore, the subsequent versions of MEPP were built at PF using GPE (Sredneuralskaya, Roskar, etc.). Since the PF workshops have sanitary breaks (at least $300 \mathrm{~m}$ ) for sanitary requirements, it is necessary to decentralize the MEPP and install local container modular MEPP for large areas connecting them to factory low-voltage networks with a specific power providing the necessary loads. For example, ChBF used network $10 / 0.4 \mathrm{kV}$ transformer substations and $10 \mathrm{kV}$ transmission lines along with the arrangement of accounting and payment for overflows of the SS-TLSS network and common electricity channel for the distribution of MEPP capacity of $1.25 \mathrm{MW}$ to the workshops, which are $0.5-1.2 \mathrm{~km}$ distant.

Figure 1 shows the schemes of electricity generation at network CHP.

The mini-CHP scheme with a gas piston engine and an electric generator (according to Figure 2) and later implemented by the Sredneuralskaya poultry farm showed itself as the most efficient.

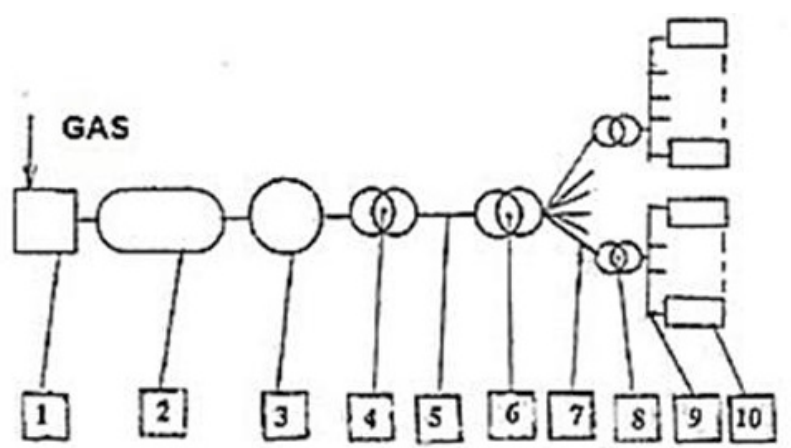

Fig. 1. Scheme of electricity generation at network CHP (1 steam boiler, 2 - steam turbine, 3 - electric generator, 4 - 6 (10) / $35(110,220) \mathrm{kV}$ transformer, $5-35(110,220) \mathrm{kV}$ transmission line, 6 - $35(110,220) / 6(10) \mathrm{kV}$ transformer, 7 6 (10) $\mathrm{kV}$ transmission line, 8 - 6 (10) / $0.4 \mathrm{kV}$ transformer, 9 $0.4 \mathrm{kV}$ transmission line, 10 - electricity consumer (poultry houses), 11 - mini-EPP (GPE + EG)).

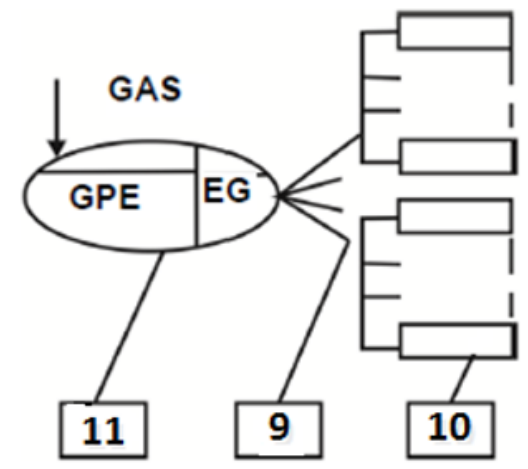

Fig. 2. Scheme of electricity generation at mini-electric power plants (MEPP).

In terms of gas limits for MEPP, engines operating on other available fuel can be used, for which the machine-building industry of the Russian Federation has developed engines working on crude oil. The first of them have also been successfully operated for over twenty years in the oil fields of Siberia.

\section{Conclusions}

Prospects for the power industry require the development and implementation of effective ways to improve the efficiency of energy supply and energy consumption, including through the development of alternative electricity, which is capable of providing a "multiple" reduction in the price of a kilowatt-hour.

The simulation showed that the mini-CHPs should be installed into separate sections with an extremely high daily demand factor for connected loads and the generator power should be selected for the loads of a specific area.

The Cherepovets poultry plant began to save substantial amounts of heat (and gas) by installing heat recovery unitsat a large number of poultry houses, so that one of the DKVR steam boilers was without any load. This made it possible to install a turbine generator in a separate room at the boiler house and eliminate the problems of limits to the mini-CHP gas amount and connection.

The modernization allowed the Cherepovets poultry farm to produce annually up to one third of its own electricity, to keep the cost price of the generated $\mathrm{kWh}$ three times lower than the grid cost price.

\section{References}

[1] V.E. Fortov, O.N. Favorsky, State main problems of the power industry of the Russian 
Federation: RAS Energy sector of Russia. Problems and prospects (Moscow: Science) 13-20 (2006)

[2] Report of the Presidium of the Russian Academy of Sciences: Moscow: RAS Energy of Russia. Problems and prospects (Moscow: Science) 499 (2006)

[3] A.A. Makarov, Scientific and technical forecasts and problems of the development of the energy sector of Russia until 2030 Bulletin of the Russian Academy of Sciences 3, 206-215 (2009)

[4] E.P. Volkov, V.A. Barinov, Prospects for the development of electric power industry in Russia in the period up to 2030 News of the Russian Academy of Sciences: Energy 1, 18-32 (2008)

[5] V.A. Akulinichev, Renewable energy resources of the Ocean RAS Energy of Russia. Problems and prospects (Moscow: Science) $325-5$ (2006)

[6] M.P. Fedorov, Artificial renewable energy sources News of the Russian Academy of Sciences.Energy 2, 6 - 10 (2009)

[7] A.E. Sheidlin, V.Z. Zhuk, The concept of aluminum hydrogen energy RAS.Energy of Russia. Problems and prospects (Moscow: Science) 423-9 (2006)

[8] N.N. Ponomarev-Stepnoy, Nuclear power engineering and its future RAS. Energy of Russia. Problems and prospects 61-68 (2008)

[9] The main provisions (Concept) of the technical policy in the power industry of the Russian Federation for the period up to 2030 New in the Russian electric power industry 2, 5-14 (2008)

[10] Federal Law 35-FZ, "On Electric Power Industry" Rossiyskaya Gazeta 3174 04/01/2003 (2003)

[11] Federal Law 261-FZ, of November 23 "On Energy Saving and Energy Efficiency Improvement ..." Rossiyskaya Gazeta" 5050 (2009)

[12] Government Decision 442, of the Russian Federation dated 04/05/2012. "On the functioning of retail electricity markets ..."'Rossiyskaya gazeta 5778 11.11.2012

[13] Decree 643, of the Government of the Russian Federation "On the Rules of the Wholesale Electricity (Capacity) Market for the Transition Period" Collection of Legislation Issue 44 (2003)

[14] S.A. Sarkisov, Analysis of the main features of the collection of periodic data types in modern metering systems Science, technology and education (Ivanovo: Olympus Publishing House) 11(17), $46-9$ (2015)

[15] Ya. Urinson, New tariff policy of RAO "UES of Russia” Energy Market 1, 25 - 9 (2004) 